\title{
DIFFERENTIAL EFFECTS OF CHRONIC IRON DEFICIENCY ANAEMIA ON JUNCTIONAL AND LABYRINTHINE ZONES OF PLACENTA IN SPRAGUE DAWELY RAT
}

\author{
Omer Awad Msc, Abdel Malek Msc, PhD, Julius Ogeng'o PhD, MD, \\ Correspondence to Prof. Julius Ogeng'o Department of Human Anatomy, University of Nairobi. P.O. \\ BOX 30197 Nairobi, Tel: 0720837592 Email: jogengo@uonbi.ac.k
}

\begin{abstract}
Iron deficiency anaemia causes adverse pregnancy outcome. Studies reveal its generalized effects on histomorphometry of the placenta, without details on specific zones nor effect of gestational age. These data are important for planning intervention. This study was, therefore, designed to describe the histomorphometric changes associated with iron deficiency anaemia on placenta of albino rat. Fourty nine (49) Sprague - Dawely albino rats were randomly separated into experimental and control groups. The experimental group was rendered anaemic by removing $1.5 \mathrm{ml}$ of blood per bleed on five alternate days. Placentas were collected on gestational days 17,19 and 21. Five cubic milimetre segments were fixed in $10 \%$ buffered formaldehyde solution; dehydrated in ethanol and embedded in paraffin wax. Five micron thick sections were cut, deparaffinized and stained with Hematoxylin and Eosin. Micrographs were taken using Leica ICC 50 digital photomicrographic camera attached to a computer at magnification $\times 40$ and the thickness of the labyrinth and junctional zones measured. Student $t$ - test was used to compare values for the experimental and control groups. The labyrinth in the chronic anaemia group was thinner than in the control group at gestational days 17, 19 and 21 . The junctional zone, on the other hand, was consistently thicker in anaemic than in the control animals. The difference in thickness of junctional zone varied with gestational age. At gestational day 17, the zone was significantly thicker in the anaemic group $(628.9 \mu)$ than in the control $(381 \mu)$. On day 19 and 21, however, the difference was not statistically significant. In conclusion, the effects of chronic iron deficiency anaemia on the labyrinth differ from those on the junctional zone of the placenta. This differential effect appears to depend on the function and gestational age. The decrease in thickness of the labyrinth may be designed to maintain placental diffusion capacity while increased thickness of the junctional zone constitutes a compensatory physical and nutritional adaptation to hypoxia.

Key words: placenta, labyrinthine, junctional zones, thickness, anaemia.
\end{abstract}

\section{INTRODUCTION}

The placenta of rats, like that of humans, has maternal and fetal components. The maternal component is made of decidua basalis and metrial glands. The fetal components comprise the labyrinth zone (LZ) and junctional zone (JZ) [Coan et al., 2004; Furukawa et al., 2014]. The LZ, containing maternal blood spaces, trophoblastic cells and fetal capillaries constitutes the ultimate barrier where fetomaternal exchange occurs. The JZ, on the other hand, comprising spongiotrophoblast, trophoblastic giant and glycogen cells forms the structural component involved in metabolic and endocrine functions (Cline et al., 2014; Furukawa et al., 2014). As pregnancy progresses, the LZ becomes more prominent in structure and function, while the other parts diminish (Takata et al., 1997). Chronic iron deficiency anaemia (IDA) in pregnancy is associated with preterm delivery, low birth weight, inferior neonatal health (Allen, 2000; Noronha, et al., 2010; Kiran, et al. 2014; Sabina, et al. 2015). It causes abnormal placental histomorphometric changes which include reduction in size, decrease in villous vascularity, increased syncytial knots, fibrinoid necrosis and reduction in placental cotyledons (Mongia, et al. 2011; Adil, 2012; Agarwal, et al. 2013; Soni and Nair et al. 2013; Biswas, et al. 2014). Studies on these changes have addressed either the labyrinthine or junctional zones individually without details of comparative effects

Submitted $7^{\text {th }}$ October 2016, revised on $7^{\text {th }}$ November 2016. Published online $12^{\text {th }}$ December 2016. To cite Awad O, Malek A, Ogeng'o J. 2017. Differential effects of chronic iron deficiency anaemia on junctional and labyrinthine zones of placenta in sprague dawely rat. Anatomy Journal of Africa. 6: $840-846$. 
nor influence of gestational age. These data are useful in determining intervention and control measures for mitigating the effects of IDA on fetal outcome. This study, therefore, aimed at describing the effects of IDA on placental histomorphometry and how these vary between zones and with gestational age.

\section{MATERIALS AND METHODS}

This experimental study was carried out on (49) female Sprague-Dawely rats. The animals, derived from a generation of clones over 19 year period were obtained from the Department of Biochemistry, University of Nairobi. The animals were divided into control and experimental dams. Chronic anaemia was induced by withdrawing $1.5 \mathrm{ml}$ of blood on five alternate days, through the retrobulbar plexus according to the protocol by Markovic et al (2009). Anaemia was diagnosed when the haemoglobin level dropped below $12 \mathrm{~g} / \mathrm{dl}$. They were anaesthetised by ether inhalation. The abdomen was opened using a midline incision, the uterus exposed and placentas extracted on days 17, 19 and 21 (Table 1).

The placentas were cut into $5 \mathrm{~mm}^{3}$ pieces, fixed in $10 \%$ buffered formaldehyde solution; dehydrated in alcohol, cleared in xylene and embedded in paraffin wax. Five micron sections were cut, deparaffinized and stained with Hematoxylin and Eosin.

Light microscopic sections were examined at various magnifications in control and anaemic rats using a Leica ICC 50 microscope, and pictures taken with a digital camera attached to a computer. The histological zones of interest in the study were the Labyrinth and Junctional Zones.
The final sample size of 28 micrographs was selected as follows: eight (8) micrographs of Day 17, nine (9) micrographs of Day 19 and 11 micrographs of Day 21. Each micrograph was then subjected to 10 random measurements and their values recorded in millimeters. The process was repeated for the two zones under investigation for the three gestational periods. To obtain the average zone estimates on each micrograph; the total values combined were divided by 10 which was the number of times each zone was measured. The final values which were in millimeters were converted into microns using the magnification scale appearing on the micrographs. Thus each micrograph represented the average estimate of the Labyrinth and Junctional zones.

The data was analysed using SPSS Version 22. Simple descriptive statistics was performed to obtain the means and the standard errors for the zones. Independent student t-test was applied as the main inferential statistics. Graphical and numerical exploration of bivariate variables was achieved using summary tables. The means and the standard errors were presented in simple tables. The data are presented in tables and micrographs.

Table 1: Distribution on rats on different gestational days

\begin{tabular}{lll}
\hline Day & \multicolumn{2}{c}{ Number of rats } \\
\hline & Control & Experimental \\
17 & 6 & 5 \\
19 & 5 & 8 \\
21 & 13 & 12 \\
Total & $\mathbf{2 4}$ & $\mathbf{2 5}$ \\
\hline
\end{tabular}

\section{RESULTS}

Various effects of anaemia were observed on histomorphometric parameters of the labyrinth and junctional zones. The labyrinth in chronic anaemia groups was thinner in experimental than in the control group on all the days. On day 17, the thickness was $1556.6 \pm 55 \mu$ in the anemic group compared to
$2180.8 \pm 165.6 \mu$ in the controls. This difference was statistically significant $[p=0.002]$. The difference persisted through day 19 . By day 21, it was highest, being $1740 \pm 125 \mu$ in the anaemic group and 2347.6 $\pm 185.8 \mu$ in the control $(\mathrm{p}=0.024)$ [Table 1; Fig 1]. 


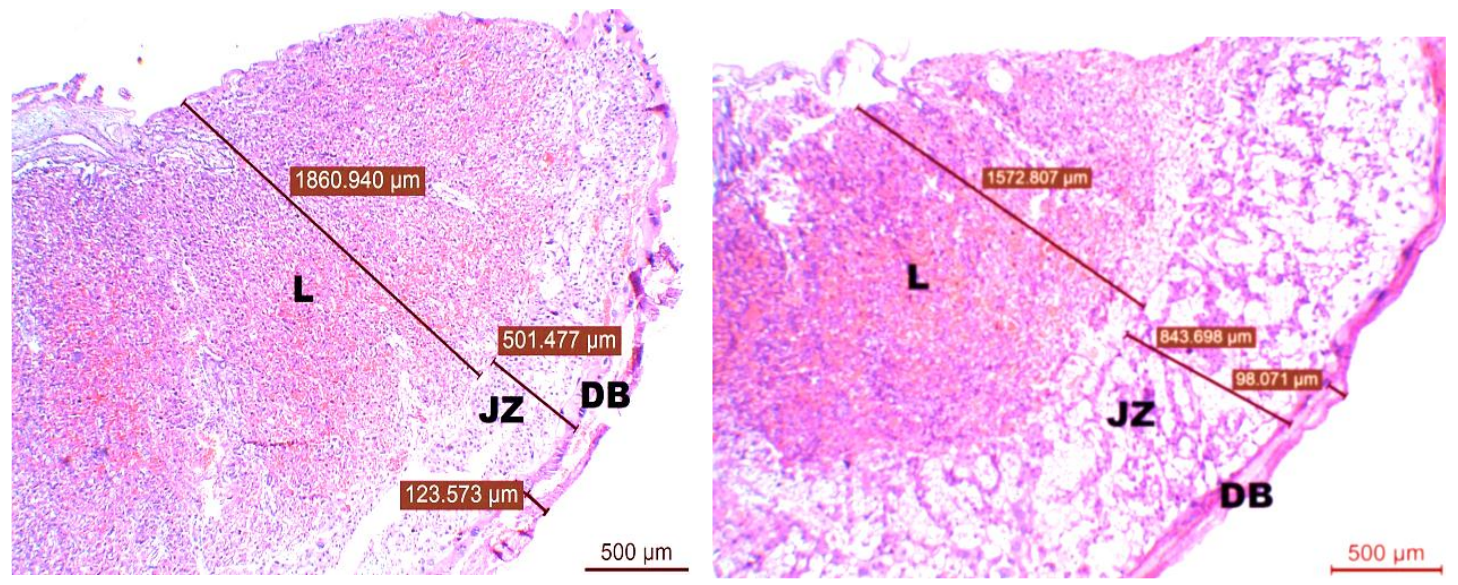

(A)

(B)
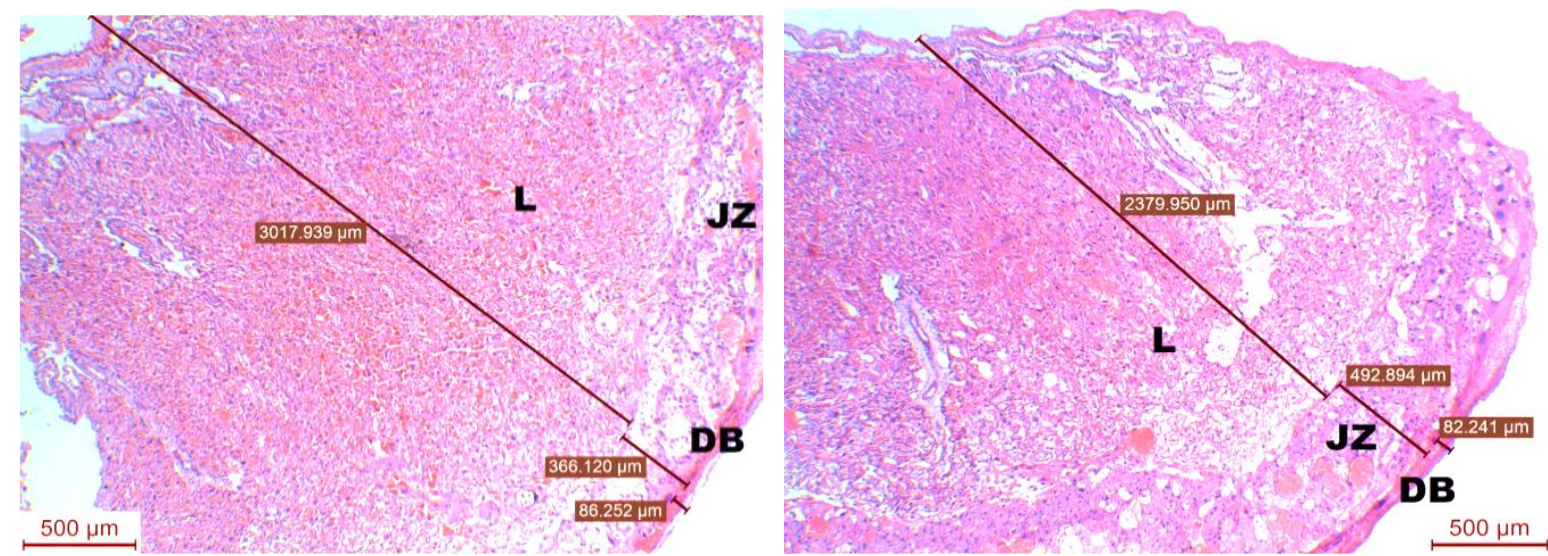

(C)

(D)

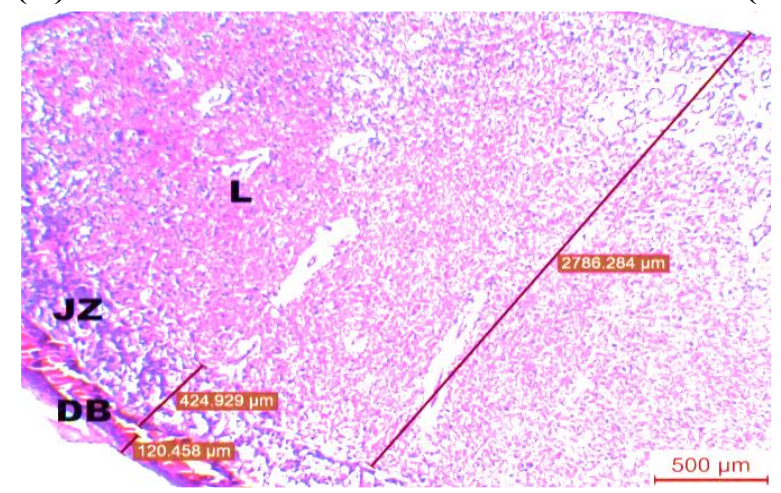

(E)

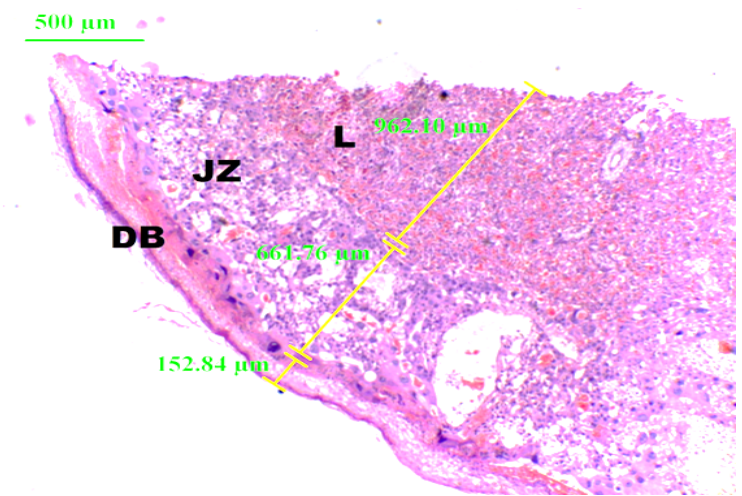

(F)

Fig 1: Micrographs of rat placenta showing Labyrinth and Junction zone. (HE, $\mathrm{x} 40$ ). L = Labyrinth; $\mathrm{JZ}=$ Junctional Zone; DB = Decidia basalis. A - Control at gestational day 17. B - Anaemic at gestational day 17. C - Control gestational day 19. D - Anaemic at gestational day 19. E - Control at gestational day 21. F - Anemic rat placenta at gestational day 21. Note: The lower thickness of L in $\mathbf{B}, \mathbf{D}$ and $\mathbf{F}$ compared to $\mathbf{A}, \mathbf{C}$ and $\mathbf{E}$; and higher thickness of $\mathrm{JZ}$ was thicker in $\mathbf{B}, \mathbf{D}$ and $\mathbf{F}$ compared 
Table 2: Effect of chronic anaemia on the thickness of the labyrinth zone

\begin{tabular}{lllll}
\hline Gestation day & \multicolumn{4}{c}{ Mean Labyrinth thickness \pm SE $(\mu)$} \\
\hline & Control & Chronic anaemia & Difference & $P$ value \\
\hline Day 17 & $2180.8 \pm 165.6$ & $1556.6 \pm 55$ & 624.2 & .002 \\
Day 19 & $2133.5 \pm 94.5$ & $1850 \pm 34.3$ & 283.5 & .014 \\
Day 21 & $2347.6 \pm 185.8$ & $1740.1 \pm 125.1$ & 634.5 & .024 \\
\hline
\end{tabular}

The junctional zone on the other hand, was consistently thicker in the anaemic than the control animals. The difference varied with gestational age. At gestational day 17 the zone was significantly thicker in the anaemic group $(628.9 \mu)$ than in the control group $(381 \mu)$. On day 19 and 21 , however, the difference was not statistically significant [Table 2]; [Fig 1]

Table 3: Effect of chronic anaemia on the thickness of junction zone

\begin{tabular}{lllll}
\hline Gestation day & \multicolumn{4}{c}{ Mean Junction zone thickness \pm SE $(\mu)$} \\
\hline Day 17 & Control & Chronic anaemia & difference & P value \\
Day 19 & $381 \pm 55.5$ & $628.9 \pm 70.3$ & 247.9 & .040 \\
Day 21 & $580 \pm 26$ & $686.6 \pm 38.2$ & 106.6 & .476 \\
\hline
\end{tabular}

\section{DISCUSSION}

Observations of the present study reveal that chronic anaemia affects the histomorphometry of the labyrinth and junctional zones. The decrease in labyrinth thickness in chronic anaemia observed in the current study is consistent with reports of other studies (Reshetnikova et al., 1994; 1995; 1997; Mayhew, 1998). The labyrinth is the zone where maternal blood comes in close contact to the fetal blood (Furukawa, et al. 2011) and the only site for nutrient, gas and waste exchange between maternal and fetal circulation (Lu et al., 2013). Accordingly, the reduction in thickness may be an adaptation to maintain the diffusion capacity of the membrane even when there is hypoxia. Pertinent to this suggestion are reports that anaemia predisposes to hypoxia (Hupertiz, 2008; Toblli et al., 2012) to which the placenta responds by remodeling its tissue components (Sankar et al., 2012; Lelic et al., 2014).

The junctional zone was thicker in anaemic rats. This is also consistent with reports from other studies (Lewis et al., 2001; Rosario et al., 2008; Sankar et al., 2012). This increase may be a response to hypoxia which causes endovascular trophoblast invasion (Rosario et al., 2008) and increase in the vasculosyncitial membrane occasioned by increased number of capillaries (Lelic et al., 2014). It may also be due to increase in the amount of glycogen cells as a compensatory mechanism to supplement the food reserves for the malnourished fetuses. Barash and
Shafrir (1990) postulated that the main source of energy for the placenta comes from glucose, which may, therefore, use the glycogen stored. Moreover, the glycogen stores may be also destined for the fetus. In the final stage of gestation, the glycogen reserves can be converted into glucose and be released directly into the maternal blood, which eventually circulates back through the labyrinth, hence explaining the relative reversion of JZ thickness with advancing pregnancy.

The most remarkable finding of the present study was the differential effect of anaemia on the morphology of LZ and JZ. Chronic anaemia decreased the thickness of LZ while increasing that of the JZ. Previous studies have considered effect of IDA on either, but not both zones (Lewis et al., 2001), making comparison difficult. Considering that anaemia is thought to affect placental structure through hypoxia, the findings of the present study are at variance with reports that hypoxia increases both LZ and JZ (Ho Chen et al., 2006; Rosario et al., 2008). These findings are also discordant with studies which reported that hypoxia increases LZ volume, while decreasing JZ volume (Higgins et al., 2015; Skeffington et al., 2015). Similar disparities in morphometric features of two zones have, however, been reported in high fat diet and undernutrition (Coan et al., 2010; Mark et al., 2011; Schulz et al., 
2012). These disparities are attributable to differences in function, stage of development and maturation (Sferruzzi - Perri et al., 2011; Sferuzzi - Perri and Camm, 2016). Several studies on rats have suggested, for example, that there may be active preservation of the placental transport function at the expense of formation of placental endocrine region to optimize substrate delivery to the fetus at particular stages of development (Mark et al., 2011; Schulz et al., 2012).

The histomorphometric changes were dependent on the gestation age. This has seldom been reported. The findings are, nonetheless, concordant with those caused by other insults such as hyperlipidemia and hyperglycaemia. In this cases, the placental interhaemal barrier, for example, is thicker but with reduced vascularity on day 16 . By day 19 , however, the barrier has become thinner and vascularity has reverted to normal (Sferruzi - Perri et al., 2013). Labyrinth thickness was significantly reduced in chronic anaemia in gestational days 17, 19 and 21 . Reduction in labyrinth thickness implies decreasing the surface area and mass of vascularity available for nutrient and gas exchange between the mother and the fetus.

Reshetnikova, et al. (1995) showed that the placenta in the third trimester adapts to severe anaemia by thinning of the villous membrane so that its diffusion capacity is maintained at normal levels, rather than changing its volume. The junctional zone in anaemic placenta was significantly increased at gestational day 17, whereas at gestational days 19 and 21 the difference was not significant. These findings are consistent with the variations in placental functional activity with gestational age (De Rijk et al., 2002) and underscore the importance of the influence of gestational age on the effects of IDA.

\section{CONCLUSION}

The effects of chronic iron deficiency anaemia on the labyrinth differ from those of the junctional zones of the placenta. The differential effect appears to depend on the function and gestational age. The decrease in thickness of the labyrinth may be designed to maintain placental diffusion capacity while increase in thickness of the junctional zone constitutes a compensatory physical and nutritional adaptation to hypoxia.

\section{ACKNOWLEDGEMENT}

We are grateful to technical staff in the Departments of Biochemistry and Human Anatomy for technical support, Prof Oduor - Okello for expert advice and Antonina Odock - Opiko for typing the manuscript.

CONFLICT OF INTEREST: There is no conflict of interest

\section{REFERENCES}

1. Adil SAK. 2012. A study of histopathological changes of placenta in severe anaemia. Jevol Med Dent Sci; 1: 616- 623.

2. Agarwal KN, Gupta V, Agarwal S. 2013. Effect of maternal iron status on placenta, fetus and newborn. IJMMS; 5:391-395

3. Allen L. 2000. Anemia and iron deficiency: effects on pregnancy outcome. Am J Clin Nutr; 71: 1280 1284.

4. Barash V, Shafrir E. 1990. Mobilization of placental glycogen in diabetic rats. Placenta; 11: 515-521.

5. Biswas S, Meyur R, Kundu, P. 2014. Placental changes associated with maternal anaemia. Eur J Anat; 18: 165-169.

6. Cline J, Dixon D, Ernerudh J, Faas M, Gohner C, Hager JD et al. 2014. The placenta in toxicology. Paper III: Pathological assessment of the placenta. Toxicol Path; 42: 339 - 344.

7. Coan P, Ferguson - Smith A, Burton G. 2004. Developmental dynamics of the definitive mouse placenta assessed by stereology. Biol Reprod; 70: 1806 - 1813.

8. Coan PM, Vaughan OR., Sekita, Y., Finn, S. L., Constancia, M., \& Burton, G. J. 2010. Adaptations in placental phenotype support fetal growth during undernutrition of pregnant mice. J. Physiol; 588: 527-538.

9. De Rijk EP, Van Esch E, Flik G. 2002. Pregnancy dating in the rat: Placental morphology and maternal blood parameters. Toxicol Pathol; 30: $271-282$.

10. Furukawa S, Hayashi S, Usuda K, Abe M, Hagio S, Ogawa I. 2011. Toxicological pathology in the rat placenta. J Toxicol Pathol;24: 95-111. 
11. Furukawa S, Kurodal Y, Sugiyama A. 2014. A comparison of the histological structure of the placenta in experimental animals. J Toxicol Pathol; 27: $11-18$.

12. Higgins JS, Vaughan OR, de Liger EF, Fowden AL, Sfferuzzi - Perri EN. 2015. Placental phenotype and resource allocation to fetal growth are modified by the timing and degree of hypoxia during mouse pregnancy. J Physiol; 594: 1341 - 1356.

13. Ho-Chen JK, Ain R, Alt AR, Wood JG, Gonzalez NC, Soares MJ. 2006. Hypobaric hypoxia as a tool to study pregnancy-dependent responses at the maternal-fetal interface. Methods Mol Med; 122: 427-434.

14. Huppertz B. 2008. Placental origins of preeclampsia challenging the current hypothesis. Hypertension; 51:970-975.

15. Kiran N, Zubair A, Khalid H, Zafar A. 2014. Morphometrical analysis of intervillous space and villous membrane thickness in maternal anaemia. J Ayub Med Coll Abbottabad; 26: 207 - 211.

16. Lelic M, Bogdanovic G, Ramic S, Brkicevic E. 2014. Influence of Maternal Anemia During Pregnancy on Placenta and Newborns. Med Arch; 68: 184-187.

17. Lewis RM, Dohertya CB, James LA, Burton GJ, Hales CN. 2001. Effects of maternal iron restriction on placental vascularization in the rat. Placenta; 22:534- 539.

18. Lu J, Zhang S, Nakano H, Simmons DG, Wang S, Kong S, et al. 2013. A positive feedback loop involving Gcm1 and Fzd5 directs chorionic branching morphogenesis in the placenta. PLoS Biol.11: e1001536

19. Mark PJ, Sisala, C, Connor K, Patel R, Lewis JL, Vickers M, et al. 2011. A maternal high-fat diet in rat pregnancy reduces growth of the fetus and the placental junctional zone, but not placental labyrinth zone growth. J Dev Orig Hlth Dis; 2: 63-70.

20. Markovic S, Milosevic M, Dordevic N, Ognjanovic B, Stajn AS, Zorica S. 2009. Time course of hematological parameters in bleeding induced anemia. Arch Biol Sci Belgrade, 61: 165 - 170.

21. Mayhew TM. 1998. Thinning of the intervascular tissue layers of the human placenta is an adaptive response to passive diffusion in vivo and may help predict the origin of fetal hypoxia. Eur J Obstet Gynecol Reprod Biol;81:101-109.

22. Mongia SM, Kumar JS, Mukesh Y. 2011. Placenta: The wonder organ: J Indian Acad Forens Med; 33: 140 -142 .

23. Noronha JA, Bhaduri A, Vinod H, Kamath A. 2010. Maternal risk factors and anaemia in pregnancy: a prospective retrospective cohort study. Obstet Gynaecol; 30:132-136.

24. Reshetnikova OS, Burton GJ, Milovanov AP. 1994. Effect of hypobaric hypoxia on the fetoplacental unit: the morphometric diffusing capacity of the villous membrane at high altitude. Am J Obstet Gynecol; 171:1560 - 1565 .

25. Reshetnikova OS, Burton GJ, Teleshova OV. 1995. Placental histomorphometry and morphometric diffusing capacity of the villous membrane in pregnancies complicated by maternal iron-deficiency anemia. Am J Obstet Gynecol;173:724-727.

26. Rosario GX, Konno T, Soares MJ. 2008. Maternal hypoxia activated endovascular trophoblast cell invasion. Developmental Biology; 314:362 - 375.

27. Roshetnikova OS, Burton GJ, Milonov AP, Teleshov OV. 1997. Human placental barrier remodeling under different type of hypoxia. Arkh Patol; 59:50 - 53.

28. Sabina S, Iftequar S, Zaheer Z, Khan M, Khan S. 2015. An overview of anemia in pregnancy. JIPBS; 2:144151.

29. Sankar KD, Bhanu PS, Kiran S, Ramakrishna BA, Shanthi V. 2012. Vasculosyncytial membrane in relation to syncytial knots complicates the placenta in preeclampsia: a histomorphometrical study. Anat Cell Biol; 45:86-91.

30. Schulz LC, Schlitt JM, Caesar G, Pennington KA. 2012. Leptin and the placental response to maternal food restriction during early pregnancy in mice. Biol Reprod; 87, 120.

31. Sferruzi - Perri AN, Camm EJ. 2016. The programming power of the placenta. C Amm EJ Front Physiol;7: 33 
32. Sferruzzi-Perri AN, Vaughan OR, Coan PM, Suciu MC, Darbyshire R, Constancia M., et al. 2011. Placental-specific Igf2 deficiency alters developmental adaptations to undernutrition in mice. Endocrinology; 152: 3202-3212.

33. Sferruzzi-Perri AN, Vaughan OR, Haro M, Cooper WN, Musial B, Charalambous M et al. 2013. An obesogenic diet during mouse pregnancy modifies maternal nutrient partitioning and the fetal growth trajectory. FASEB; 27: 3928-3937.

34. Skeffington KL, Higgins JS, Mahmoud AD, Evans AM, Sferruzzi-Perri AN, Fowden, A. L. 2016. Hypoxia, AMPK activation and uterine artery vasoreactivity. $J$ Physiol; 594: $1357-1369$.

35. Soni R, Nair S. 2013. Study of histological changes in placenta of anaemic mothers. IOSR-JDMS; 9: 4246.

36. Takata K, Fujikura K, Shin B. 1997. Ultrastructure of the rodent placental labyrinth: a site of barrier and transport. J Reprod Dev; 43: 13 - 24.

37. Toblli JE, Cao G, Oliveri L, Angerosa, M. 2012. Effects of iron deficiency anemia and its treatment with iron polymaltose complex in pregnant rats, their fetuses and placentas: oxidative stress markers and pregnancy outcome. Placenta;33:81-87. 